\title{
Dynamic Mechanical Characteristics of Impact Rock under the Combined Action of Different Constant Temperatures and Static and Dynamic Loads
}

\author{
Enlai Zhao $\mathbb{D}^{1,2}$, Enyuan Wang $\mathbb{D}^{1,2}$ Zesheng Zang, ${ }^{1,2}$ Xiaojun Feng, ${ }^{1,2}$ and Rongxi Shen ${ }^{1,2}$ \\ ${ }^{1}$ Key Laboratory of Gas and Fire Control for Coal Mines, China University of Mining and Technology, Ministry of Education, \\ Xuzhou 221116, China \\ ${ }^{2}$ School of Safety Engineering, China University of Mining and Technology, Xuzhou 221116, Jiangsu, China
}

Correspondence should be addressed to Enyuan Wang; weytop@163.com

Received 18 September 2021; Accepted 8 November 2021; Published 22 December 2021

Academic Editor: Fan Deyuan

Copyright (c) 2021 Enlai Zhao et al. This is an open access article distributed under the Creative Commons Attribution License, which permits unrestricted use, distribution, and reproduction in any medium, provided the original work is properly cited.

\begin{abstract}
The complex mechanical environment of deep coal and rock masses leads to obvious changes on their dynamic mechanical properties. However, there are few reports on the dynamic mechanical properties of rocks under the combined action of medium temperature (normal temperature $\sim 100^{\circ} \mathrm{C}$ ) and static and dynamic loads. In this paper, a dynamic load and temperature combined action Hopkinson pressure bar experimental system is used to experimentally study the impact type of a fine sandstone under temperature conditions of $18^{\circ} \mathrm{C}, 40^{\circ} \mathrm{C}, 60^{\circ} \mathrm{C}, 80^{\circ} \mathrm{C}$, and $100^{\circ} \mathrm{C}$, an axial static load of $3 \mathrm{MPa}$, a gas chamber pressure of $0.06 \mathrm{MPa}$, and a constant temperature time of $4 \mathrm{~h}$. The dynamic characteristics of the change law of the fine sandstone and the energy dissipation characteristics of the load process are analyzed, and the characteristic law of the fine sandstone surface response is analyzed using digital image correlation technology. Our results indicate the following. (1) Under conditions in which the other experimental conditions remain unchanged, the dynamic stress-strain of the fine sandstone presents a bimodal shape with a "rebound" phenomenon. Increasing temperature causes the peak strength of the fine sandstone to increase; however, the relative strength can increase or decrease. The relative increase in the strength is $1.14 \mathrm{MPa}\left({ }^{\circ} \mathrm{C}\right)$ when the temperature increases from $40^{\circ} \mathrm{C}$ to $60^{\circ} \mathrm{C}$, $0.15 \mathrm{MPa}\left({ }^{\circ} \mathrm{C}\right)$ when the temperature increases from $60^{\circ} \mathrm{C}$ to $80^{\circ} \mathrm{C}$, and $0.62 \mathrm{MPa}\left({ }^{\circ} \mathrm{C}\right)$ when the temperature increases from $80^{\circ} \mathrm{C}$ to $100^{\circ} \mathrm{C}$. (2) The digital image correlation results show that, under the action of a dynamic load stress wave, the fine sandstone experiences a displacement vector change on the sample surface; furthermore, under the combined action of the temperature and dynamic and static loads, the fine sandstone experiences macroscopic shear failure. The surface strain in the propagation direction of the stress wave is obviously higher and can even reach values of more than 10 times that of the strain in other directions. (3) From the perspective of energy dissipation, the incident energy, reflected energy, and dissipated energy of the fine sandstone under an impact load have the same change law. After being affected by a dynamic load, the energy rapidly increases to a certain value and then remains relatively stable. The transmitted energy is relatively small and can be approximated as a horizontal line. As the temperature increases, the incident energy, reflected energy, and dissipated energy tend to first decrease and then increase, and most of the incident energy in the fine sandstone is dissipated in the form of reflected waves.
\end{abstract}

\section{Introduction}

With the rapid development of the global economy, shallow Earth resources can no longer meet demand, and the development and utilization of deep resources have become the primary strategy used to solve the energy problem. According to incomplete statistics, there are more than 100 mines in China with mining depths greater than $1,000 \mathrm{~m}$. In Chinese coal fields, there are more than 50 coal mines with mining depths greater than $1,000 \mathrm{~m}[1]$, which extend deep at an average rate of $8-12 \mathrm{~m}$ per year [2] (Figure 1). The complex mechanical environment, i.e., high ground stress, high ground temperature, high osmotic pressure, and mining disturbances, causes deep coal and rock masses to 


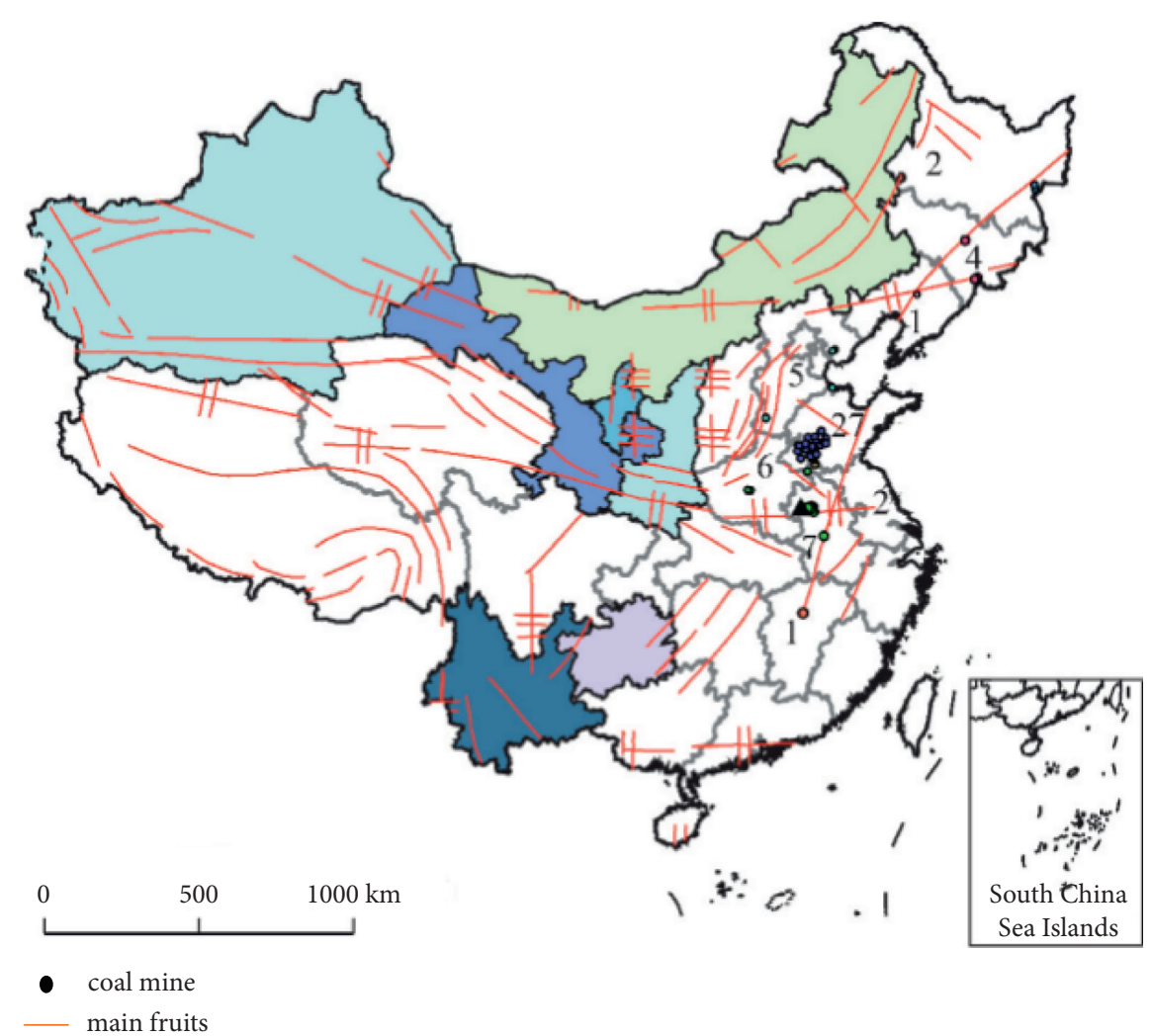

Figure 1: Geographical distribution of deep wells in coal mines in China [1].

exhibit completely different mechanical properties from those of shallow rocks $[3,4]$. In the process of deep mining, there are numerous rock fragmentation problems, including rock breakage, roof fracture, and even rock burst disasters. This makes deep coal mining challenging and restricts the safe and efficient mining of coal resources. Therefore, studying the mechanical response characteristics of rock damage and failure under the combined action of temperature and static and dynamic loads can provide a theoretical basis for controlling the surrounding rock during deep mining and has an important practical engineering value.

In terms of rock dynamic mechanics research, splitHopkinson pressure bar (SHPB) technology has become the main method for rock dynamic and static load measurements since its inception in 1949. After decades of development, SHPB technology has achieved long-term development in experimental equipment. Ellwood customized the incident pulse for a sample using a pulse shaper, improved the SHPB system, and realized constant strain rate tests of material at a high-strain rate [5]. Cui et al. analyzed the high-strain rate shear test technology of SHPB and summarized the advantages and disadvantages of this experimental method $[6,7]$. Xie et al. developed a hightemperature SHPB experimental system to study the dynamic compression mechanical properties of hydrogenresistant steel [8-10]. In terms of the development of the three-axis SHPB experimental system, Christensen [11] and Lindholm [12] successively designed a three-axis SHPB system for brittle materials, such as concrete, and Yu designed a three-axis SHPB experimental device and studied triaxial dynamic load characteristics and microscopic damage mechanisms of rocks [13]. Dou et al. designed a true triaxial impact dynamic and static load combination test machine, where the sample is subjected to a combination of dynamic and static loads in the horizontal direction [14]. Kong designed and developed an SHPB experimental system to study the impact damage of gas-containing coal and examined the dynamic characteristics of gas-containing coal under different load combinations [15]. Gilat et al. [16, 17] used SHPB technology to determine the dynamic mechanical properties and test methods for different rock materials under high-temperature conditions $\left(650-1060^{\circ} \mathrm{C}\right)$.

Scholars worldwide have applied the above-mentioned experimental system to study the dynamic mechanical properties of rocks at room temperature. Grady et al. performed dynamic impact experiments on oil shale at low and medium strain rates and found that its compressive strength increased with increasing strain $[18,19]$. Zhu and $\mathrm{Wu}[20]$ and Wang et al. [21] conducted dynamic impact experiments on rocks under one- and three-dimensional conditions and obtained a law for the dynamic strength and loading rate. Friedman analyzed the relationship between the failure strength, elastic modulus, and strain rate of granite and limestone under uniaxial compression and dynamic load conditions [22]. Janach studied the uniaxial dynamic impact characteristics of limestone and granite [23]. Li et al. [24, 25] systematically analyzed the relationship between rock dynamic mechanical properties, deformation and failure characteristics, damage and stress waves, and damage and energy dissipation via impact loading experiments on 
different types of rocks. Lou experimentally studied the average dynamic tensile strength and dynamic stress-strain relationship of dry and water-saturated granite samples [26]. Shan et al. [27] used SHPB to test the constitutive uniaxial failure relationship of granite under dynamic load conditions. Li et al. experimentally studied the impact dynamic mechanical properties of marble and analyzed the strain rate, failure time, failure mode, and stress-strain relationship during the failure process $[28,29]$. Li et al. conducted SHPB impact experiments on oil- and water-saturated sandstone and marble and analyzed the influence of the viscosity coefficient and porosity of the liquid medium on the attenuation and dispersion characteristics of the stress wave [30]. Liu et al. [31-33] discussed the instability mechanism and deformation and failure characteristics of large section caverns caused by dynamic load in deep mine using simulation method. Xia et al. [34] discussed the characteristics of energy dissipation in the impact process for man-made rocks. Zhai et al. analyzed the effects of microcrack characteristics of granite, such as the initial length, angle, initial crack spacing, and friction coefficient of the crack surface, on the dynamic strength and fracture of the material under different strain rates [35]. Liang et al. [36] discussed the dynamic strength changes of granite, sandstone, and limestone under varying strain rate conditions and sample sizes.

With respect to rock damage under the combined effect of temperature and static and dynamic loads, Song et al. studied the characteristic law of the failure strain of marble under dynamic tensile conditions after constant temperature treatments at $500^{\circ} \mathrm{C}$ and $1000^{\circ} \mathrm{C}$ [37]. Wan et al. conducted an impact test on sandstone samples after high-temperature treatment and applied the accelerated energy release theory to analyze the energy release characteristics of the imminent failure of the samples under impact loads after high-temperature [38]. $\mathrm{Li}$ studied the dynamic stress-strain characteristics, macroscopic failure characteristics, and energy dissipation characteristics of coal-measure sandstone under temperature conditions of $100^{\circ} \mathrm{C}, 200^{\circ} \mathrm{C}, 400^{\circ} \mathrm{C}, 500^{\circ} \mathrm{C}, 600^{\circ} \mathrm{C}, 700^{\circ} \mathrm{C}$, and $800^{\circ} \mathrm{C}$ [39]. Yin et al. studied the relationship between the dynamic load strength, peak strain, and temperature of granite at temperatures of $50^{\circ} \mathrm{C}, 100^{\circ} \mathrm{C}, 200^{\circ} \mathrm{C}$, and $300^{\circ} \mathrm{C}$ [40]. Shu et al. used the SHPB experimental system to perform cyclic impact loading experiments on rocks after heat treatments $\left(\right.$ at $25^{\circ} \mathrm{C}, 100^{\circ} \mathrm{C}$, $200^{\circ} \mathrm{C}, 400^{\circ} \mathrm{C}, 600^{\circ} \mathrm{C}$, and $800^{\circ} \mathrm{C}$ ) to analyze the energy dissipation, energy dissipation rate, the relationship between the number of impacts, energy consumption per unit volume, failure mode, and temperature [41]. Zhang and Jing used a SHPB device with a diameter of $50 \mathrm{~mm}$ to study the dynamic damage characteristics and energy dissipation characteristics of sandstone treated at room temperature from $-15^{\circ} \mathrm{C}$ to $1000^{\circ} \mathrm{C}$ [42]. Yu et al. conducted dynamic impact tests on marble samples after thermal damage (from $25^{\circ} \mathrm{C}$ to $900^{\circ} \mathrm{C}$ ) under vacuum and air conditions and explored the degradation mechanisms of their physical parameters and dynamic mechanical properties $[43,44]$. In summary, few scholars have used the SHPB system to study the dynamic mechanical properties and failure mechanisms of coal-measure rocks with a weak impact tendency under the combined action of static and dynamic loads in the temperature range from room temperature to $100^{\circ} \mathrm{C}$. In this paper, the SHPB system is used in combination with dynamic loads and temperatures to conduct impact dynamics experiments on fine sandstone at room temperature $\left(18^{\circ} \mathrm{C}\right), 40^{\circ} \mathrm{C}, 60^{\circ} \mathrm{C}, 80^{\circ} \mathrm{C}$, and $100^{\circ} \mathrm{C}$ and to analyze the damage process. The characteristic law of the dynamic mechanical parameters provides basic parameters to control the surrounding rock during deep mining.

\section{Experimental Design}

2.1. Experiment System. The dynamic load and temperature combined effect Hopkinson pressure bar experiment system is composed of a separate SHPB, a superdynamic strain acquisition system, a digital image correlation (DIC) analysis system, and a temperature control system, as shown in Figure 2. Figure 3 shows a schematic diagram of the installation of the constant temperature furnace during the impact test, where the observation window size is $80 \mathrm{~mm} \times 100 \mathrm{~mm}$.

2.2. Sample Preparation and Plan. The samples were extracted from fine sandstone in the roof of the Da'anshan coal mine and cut into rectangular parallelepiped shapes with a size of $40 \mathrm{~mm} \times 40 \mathrm{~mm} \times 80 \mathrm{~mm}$ in accordance with the rock dynamics standard. The sample surfaces were smooth and had no obvious defects. The static mechanical performance test and analysis indicated that the fine sandstone had a weak impact tendency and an average density of $2.38 \mathrm{~g} / \mathrm{cm}^{3}$. The samples were heated from room temperature $\left(18^{\circ} \mathrm{C}\right)$ to $40^{\circ} \mathrm{C}, 60^{\circ} \mathrm{C}, 80^{\circ} \mathrm{C}$, and $100^{\circ} \mathrm{C}$, respectively, and then impacted in the SHPB experimental device. Table 1 lists the basic parameters of the dynamic mechanics experiments.

\section{Analysis of Results}

3.1. Stress-Strain Response. Figure 4 shows the dynamic stressstrain curves of the impact-type fine sandstone samples under different temperature conditions. It can be seen that, in the design of the dynamic load experiment, the pressure of the air chamber is constant at $0.05 \mathrm{MPa}$; however, in the actual experimental process, the accuracy of the air pressure system in the impact rod launching system causes the incident speed of the bullet to change. The fluctuation range of the velocity is $1.00-1.31 \mathrm{~m} / \mathrm{s}$. Under the condition in which the other experimental parameters remain unchanged, the dynamic strength of the fine sandstone shows an increasing trend with temperature, and the dynamic elastic modulus increases from $7.4 \mathrm{GPa}$ to $15.9 \mathrm{GPa}$. The $18^{\circ} \mathrm{C}$ and $40^{\circ} \mathrm{C}$ fine sandstone samples experience an initial compaction stage during the dynamic load damage process, while the $60^{\circ} \mathrm{C}, 80^{\circ} \mathrm{C}$, and $100^{\circ} \mathrm{C}$ fine sandstone samples directly enter the elastic deformation stage at the initial stage of loading. With increasing strain, the gradient of the dynamic stress increases and then decreases. After the stress reaches its peak value, it begins to decrease, and there is an obvious "rebound" phenomenon. Under different temperature conditions, the similarities and differences of the stress-strain curves of the fine sandstone samples are primarily reflected in the presence or absence of plastic flat sections and "stress double peaks." 


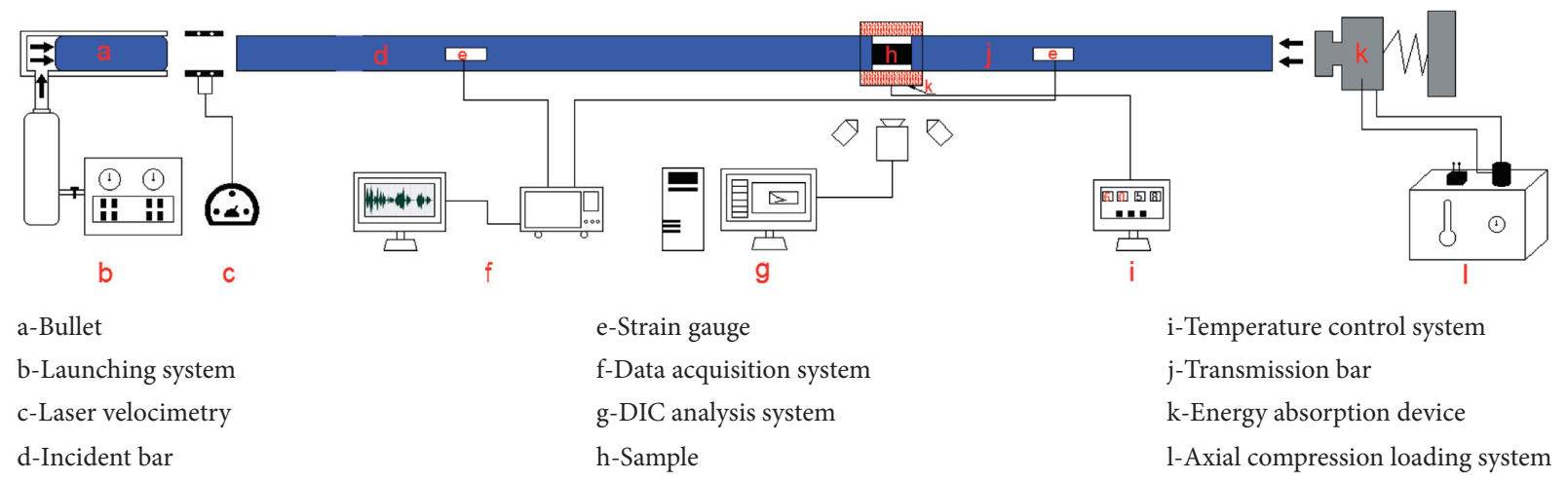

FIGURE 2: Hopkinson pressure bar experimental system under the combined action of dynamic load and temperatures. (a) Bullet. (b) Launching system. (c) Laser velocimetry. (d) Incident bar. (e) Train gauge. (f) Data acquisition system. (g) DIC analysis system. (h) Sample. (i) Temperature control system. (j) Transmission bar. (k) Energy absorption device. (l) Axial compression loading system.

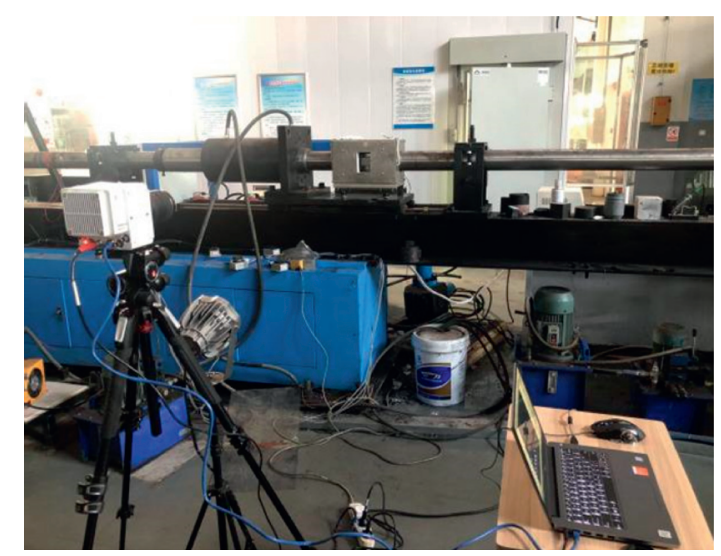

FIgURE 3: Schematic diagram of the constant temperature furnace layout.

TABle 1: Experimental parameters for the fine sandstone dynamic mechanics experiments.

\begin{tabular}{|c|c|c|c|c|c|c|}
\hline Sample No & $\begin{array}{l}\text { Chamber pressure } \\
(\mathrm{MPa})\end{array}$ & $\begin{array}{l}\text { Axial static load } \\
(\mathrm{MPa})\end{array}$ & Temperature $\left({ }^{\circ} \mathrm{C}\right)$ & $\begin{array}{l}\text { Density } \\
\left(\mathrm{g} / \mathrm{cm}^{3}\right)\end{array}$ & $\begin{array}{l}\text { Constant } \\
\text { temperature } \\
\text { time }(\mathrm{h})\end{array}$ & $\begin{array}{l}\text { Dynamic load } \\
\qquad(\mathrm{MPa})\end{array}$ \\
\hline S1 & 0.06 & 3.0 & 18 & 2.39 & 4 & 35.04 \\
\hline S2 & 0.06 & 3.0 & 40 & 2.42 & 4 & 36.16 \\
\hline S3 & 0.06 & 3.0 & 60 & 2.40 & 4 & 58.07 \\
\hline S4 & 0.06 & 3.0 & 80 & 2.37 & 4 & 61.02 \\
\hline S5 & 0.06 & 3.0 & 100 & 2.32 & 4 & 73.41 \\
\hline
\end{tabular}

The relationship between the dynamic strength, peak strain, and temperature of the fine sandstone under the action of a statistical vibration load is shown in Figure 5. The dynamic peak strength of the fine sandstone increases with temperature. In the low-temperature regime, the peak strength does not change significantly. When entering the high-temperature regime, the peak strength increases rapidly. When the temperature reaches a certain value, the peak strength remains roughly constant. The peak strain and temperature show a trend of first decreasing and then increasing. The fitting relationship for these trends is a cubic polynomial, with a correlation coefficient of up to 0.9871 .
3.2. Energy Characteristics. Based on the theory of stress wave propagation and displacement continuity, the incident energy $\left(W_{i}\right)$, reflected energy $\left(W_{r}\right)$, and transmitted energy $\left(W_{t}\right)$ during the fine sandstone impact experiment can be calculated as follows [45]:

$$
\begin{aligned}
& W_{i}=A_{0} C E \int_{0}^{\tau} \varepsilon_{i}^{2}(t) d t, \\
& W_{r}=A_{0} C E \int_{0}^{\tau} \varepsilon_{r}^{2}(t) d t, \\
& W_{t}=A_{0} C E \int_{0}^{\tau} \varepsilon_{t}^{2}(t) d t .
\end{aligned}
$$




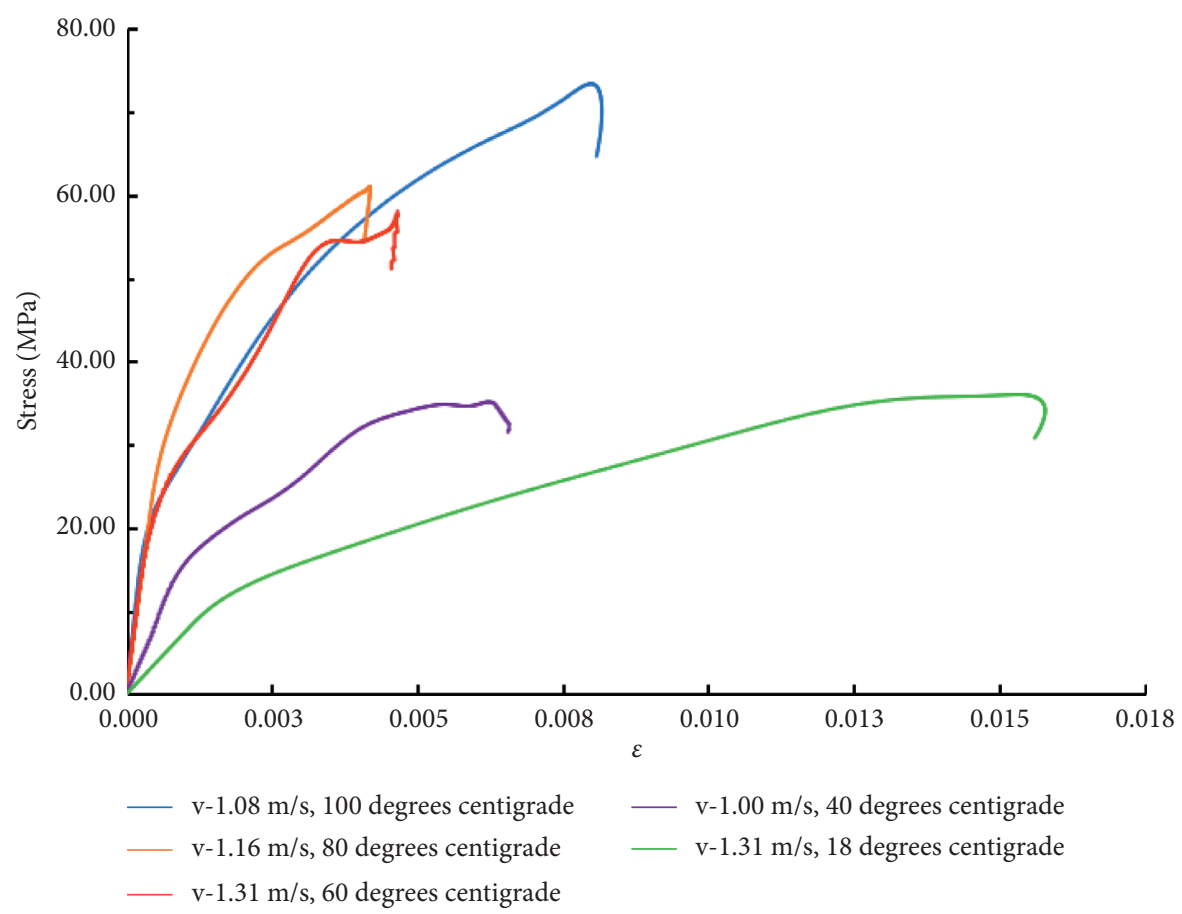

Figure 4: Dynamic stress-strain curves of the fine sandstone samples under different temperature conditions.

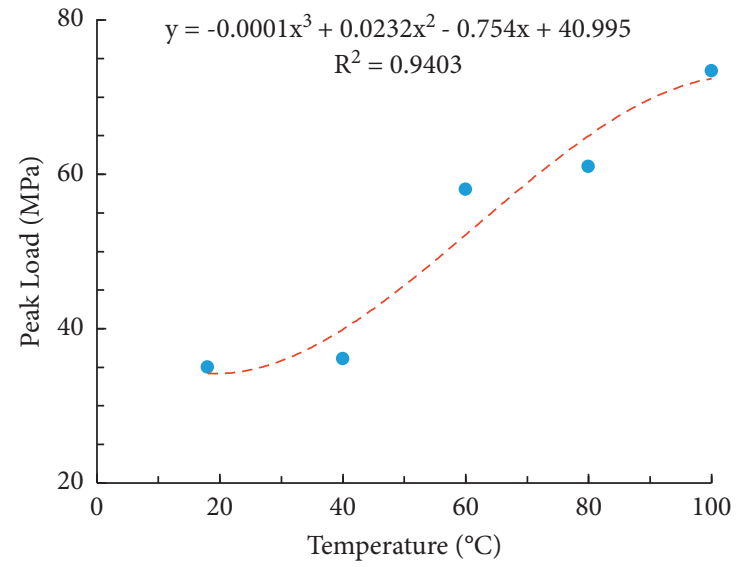

(a)

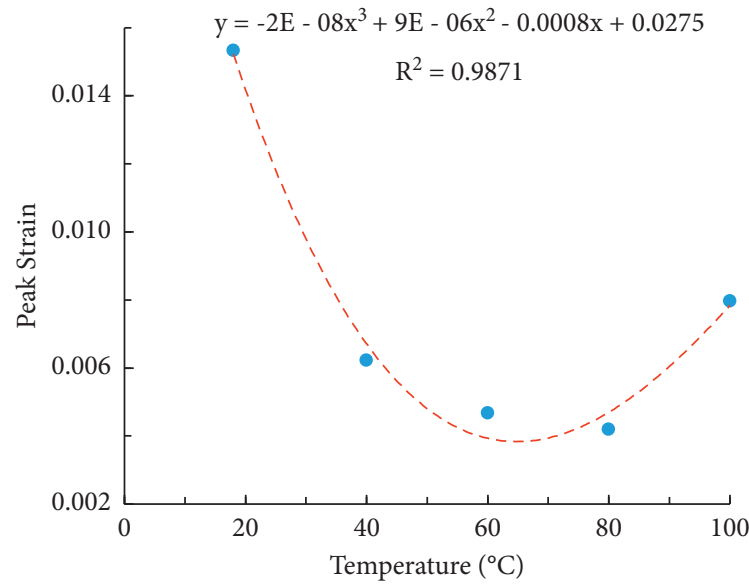

(b)

Figure 5: Relationship between dynamic the mechanical parameters of the fine sandstone and the temperature. (a) Peak load. (b) Peak strain.

Here, $C$ is the wave velocity of the stress wave in the incident rod and transmission rod, $5100 \mathrm{~m} / \mathrm{s}, E$ is the elastic modulus of the incident rod and transmission rods, $210 \mathrm{GPa}$, $A_{0}$ is the cross-sectional area of the sample, and $\tau$ is the Dynamic load time.

According to equations (1)-(3), the energy dissipation characteristics of the fine sandstone impact experiments at different temperatures can be statistically analyzed, as shown in Figure 6. Figures 6(a)-6(d) indicate that, during a single impact, the impact energy of the fine sandstone follows the pattern incident energy $>$ reflected energy $>$ dissipated energy $>$ transmission energy and that the different types of energy growth gradients have similar relationships. When the temperature increases to $100^{\circ} \mathrm{C}$ (Figure 6(e)), the energy change trend of the fine sandstone impact process changes to incident energy $>$ dissipation energy $>$ reflected energy $>$ transmission energy. A statistical analysis of the energy value (Figure 6(f)) indicates that when the temperature increases from room temperature to $100^{\circ} \mathrm{C}$, the incident energy, reflected energy, and dissipated energy show a trend of first decreasing and then increasing, while the transmission energy shows an increasing trend. In the decreasing section, the incident energy changed 


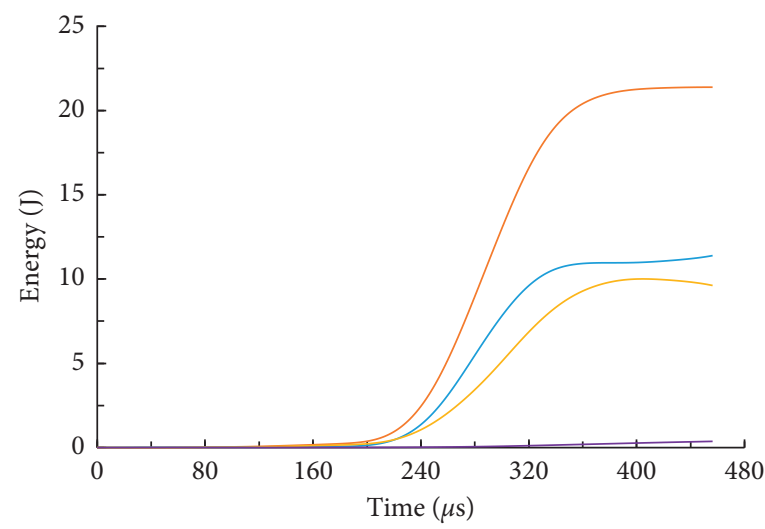

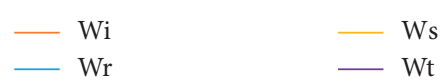

(a)
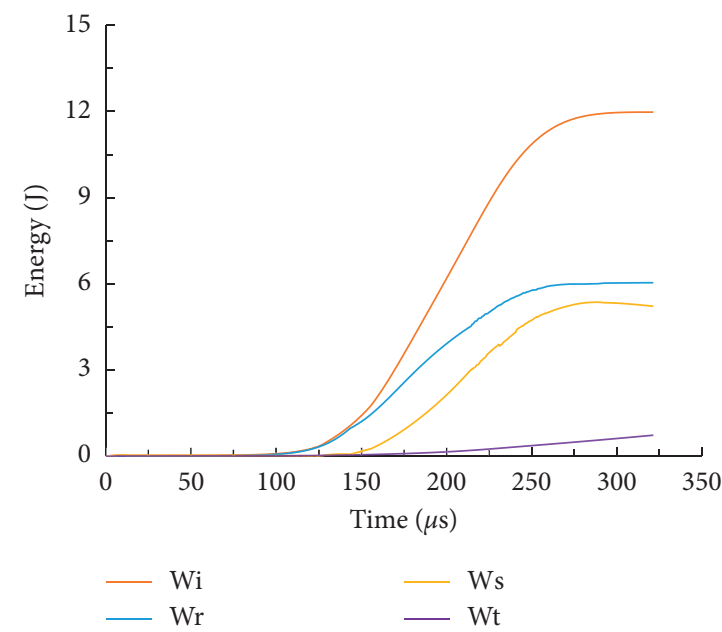

(c)
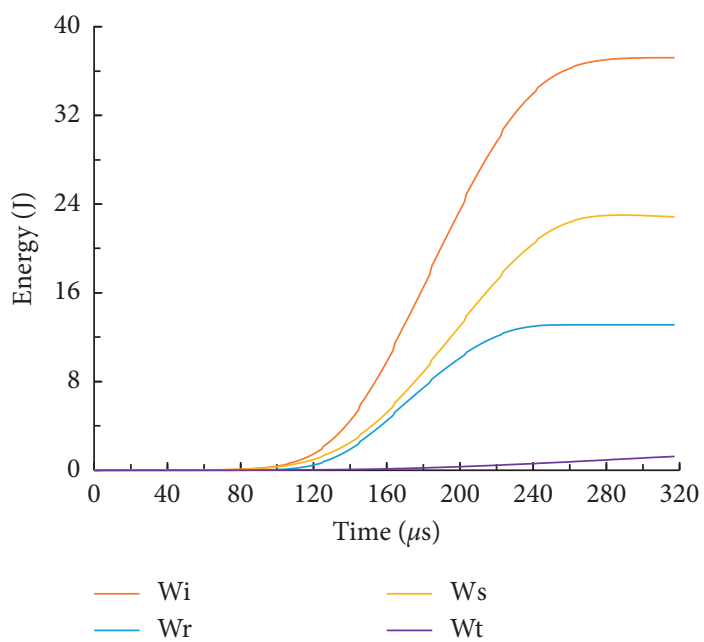

(e)

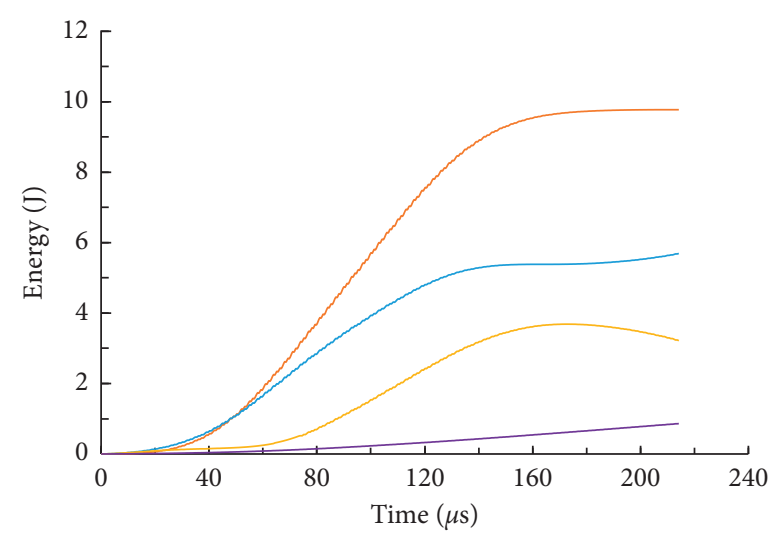

- Wi $\quad$ Ws

- Wt

(b)
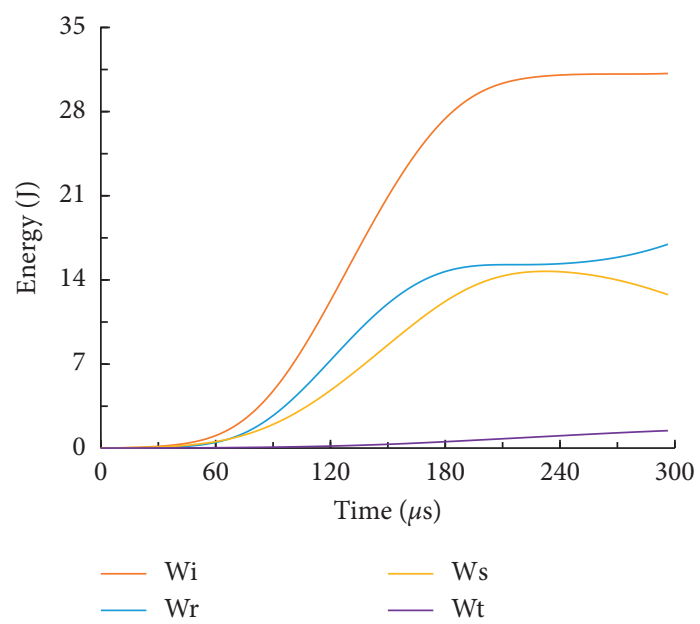

(d)

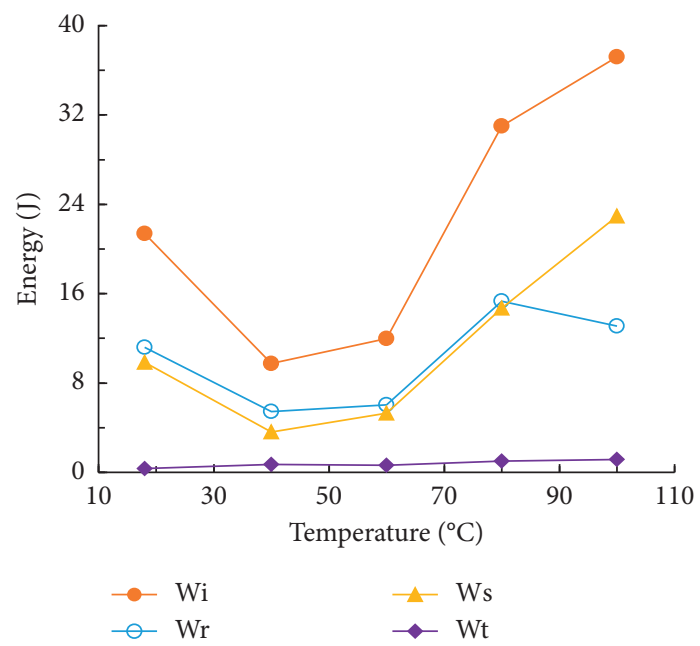

(f)

FIGURE 6: Impact energy characteristic curves of the fine sandstone samples under different temperature conditions and a statistical analysis of the energy during the impact experiment. (a) $18^{\circ} \mathrm{C}$. (b) $40^{\circ} \mathrm{C}$. (c) $60^{\circ} \mathrm{C}$. (d) $80^{\circ} \mathrm{C}$. (e) $100^{\circ} \mathrm{C}$. (f) Statistical analysis. 
from $21.37 \mathrm{~J}$ to $9.75 \mathrm{~J}$, a decrease of $54.38 \%$; the reflection energy changed from $11.19 \mathrm{~J}$ to $5.44 \mathrm{~J}$, a decrease of $51.39 \%$; the dissipation energy decreased by $63.35 \%$; and the transmission energy nearly doubled. In the increasing section $\left(40-100^{\circ} \mathrm{C}\right)$, the incident energy increased by $128.45 \%$, the reflected energy increased by $68.54 \%$, and the dissipated energy increased by $196.14 \%$. With increasing temperature, the internal dissipation energy of the fine sandstone increased significantly, reflecting the improvement in its resistance to the external load.

\subsection{Failure Mode and Strain Field Characteristics.} Figure 7 shows photos of the failure modes of the fine sandstone samples at different temperatures in the impact test. It can be seen that the impact failure mode of the fine sandstone is primarily shear failure, which is shown as the " $\mathrm{X}$ " type. There are no macroscopic primary cracks on the front of the $40^{\circ} \mathrm{C}$ and $60^{\circ} \mathrm{C}$ samples, and the backs of the samples also show the shear failure mode.

We applied DIC technology to analyze and process the surface displacement field of the $18^{\circ} \mathrm{C}$ fine sandstone sample under the action of a vibration load. Table 2 lists the parameter for the surface displacement field analysis of the fine sandstone impact experiment. In the DIC processing, the subset and step parameters were selected from the subset (11-51) and step (1-20) ranges using the built-in PA parameter optimization module. The best combination was then determined.

Figure 8 shows surface strain cloud diagrams of the fine sandstone samples under different impact stress levels after the DIC analysis. The strain coordinate system is shown in Figure $8(\mathrm{a})$. It can be seen that as the dynamic load stress increases, the strain in the $X$-direction of the specimen surface shows an increasing trend, and the range of the highstrain area gradually increases (purple area), primarily in the upper middle of the specimen surface. From Figure 8(a), we can see that the initial contact point on the right end of the specimen corresponds to the upper right corner of the shock wave that then spreads to the entire end surface. Therefore, the strain cloud diagram shows that the strain concentration area moves from the lower left corner to the upper left corner and the lower right corner. The phenomenon illustrated in Figures $8(\mathrm{a})-8(\mathrm{f})$ is the main reason why the strain concentration zone is located in the upper part of the specimen. In the poststress phase (the "rebound" section of the stressstrain curve, Figure 4), the surface strain of the sample is significantly reduced, and the high-strain area disappears. From the point of view of the peak strain in the high-strain area, the variation range is from -0.00254 to -0.001967 , an increase of $22.56 \%$. The $X$-direction strain cloud map of the fine sandstone sample can therefore describe the evolution process of the surface displacement field under a dynamic load.

Figure 9 shows $Y$-direction surface strain cloud diagrams of the fine sandstone under different impact stress levels after the DIC analysis. It can be seen that, at the initial stage of the dynamic load, the entire surface of the sample shows a positive strain trend, high-strain areas appear on the upper and lower sides of the right end surface, and the high-strain region expands as the dynamic load increases. The original positive-strain area (blue area) on the surface gradually expands toward the negative-strain area (purple area). This indicates that, under the action of the dynamic load stress wave in the $X$-direction, the displacement and strain of the sample in the $Y$-direction are related to the fluctuation characteristics of the stress wave. Comparing the strain cloud diagrams of the sample in the $X$ - and $Y$-directions, it can be seen that the strain of the sample in the $X$-direction is higher than that in the $Y$-direction.

From the analyses in Figures 8 and 9, we can see that the strain changes at different positions on the surface of the sample vary. The strains of the elements at different coordinate points on the surface of the sample were extracted for a detailed analysis. The position points and serial numbers of the extracted data are shown in Figure 10.

Figure 11 plots the horizontal and vertical strain changes corresponding to the surface position points in Regions 0,1 , and 2 in Figure 10; the abscissa indicates the number of image frames (1-6) corresponding to the dynamic load stress levels in Figure 9. It can be seen that, corresponding to the contact dynamic load stress plane of the fine sandstone (Region 2), with increasing dynamic load stress level, the horizontal strain change at the lower right end of the sample (1\#-8\#) is consistent with the propagation direction of the stress wave. Manifested as a compressive strain, the amplitude of the change gradually decreases from the edge to the center line and the strain value fluctuates in the range from -0.0004194 to 0.000382 . The horizontal strain at the upper right end of the sample (9\#-13\#) is initially subjected to a dynamic load, which is expressed as a compressive strain, and then, as the dynamic load stress increases, it is expressed as a tensile strain. The range of the change does not gradually increase from the center line to the edge. In the range of $15-90 \% \sigma \mathrm{p}$ of the stress level, the change amplitude is higher than that in the subsequent stress stage. In the postpeak stress stage, the horizontal compressive strain change is higher than the tensile strain. The strain in the vertical direction of the fine sandstone is positive, and its change direction is consistent with the direction of the $Y$-axis. There is an increasing trend with increasing dynamic load stress. There are high-strain areas at both ends of the sample: $(1 \#-3 \#)$ and $(10 \#-13 \#)$; the strain values are in the range from 0.0001 to 0.003894 ; the amplitude of the strain change in the middle area of the sample is small; and the postpeak and prepeak rules are similar. The strain changes in the middle region of the fine sandstone during dynamic loading are shown in Figures 11(c) and 11(d), corresponding to Figure 10 (Region 1). As the dynamic load stress increases, the horizontal strain of the sample generally first decreases and then increases. Overall, the sample experiences compressive strain and the strain inflection point appears at $20 \% \sigma \mathrm{p}$. The strain value fluctuates between 0.00001309 and 0.0001339 . Regions closer to the bottom of the sample experience smaller strain changes. The vertical strain of the sample shows an overall increasing trend that slightly decreases after its peak. Regions closer to the bottom of the sample experience a greater strain change. In particular, the strain values at 2\# and 3\# are negative, which is opposite to the direction of the $Y$-axis. The strain changes at the left end of the 


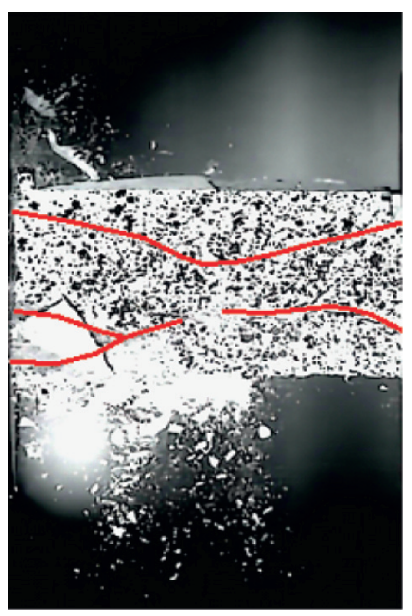

(a)

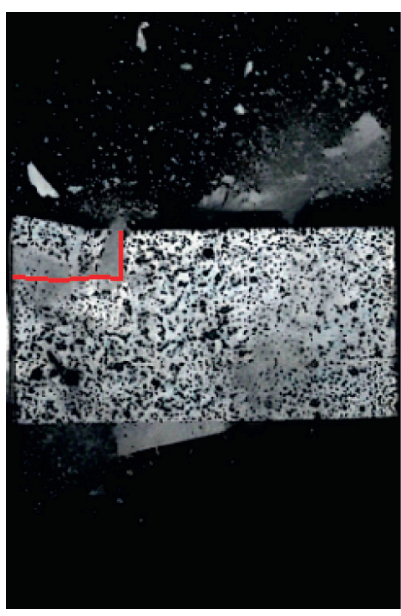

(b)

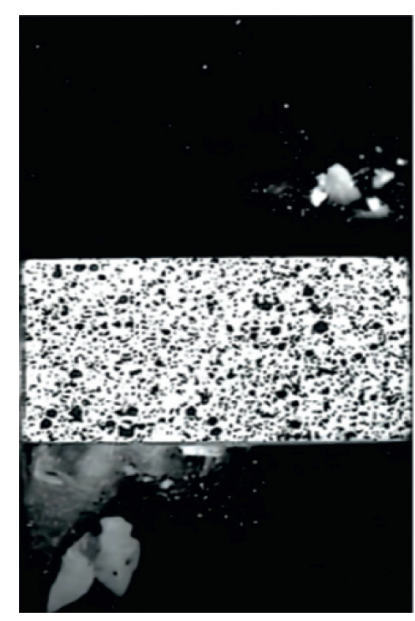

(c)

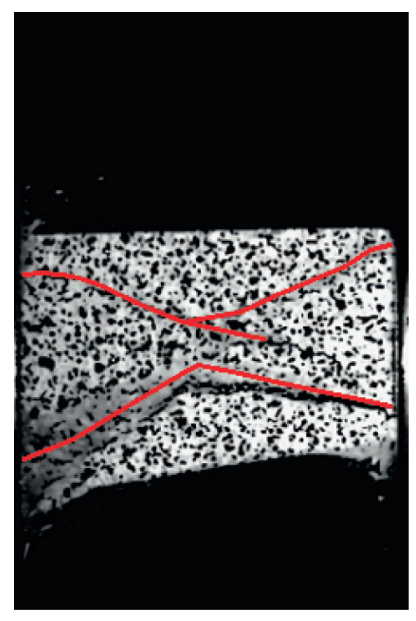

(d)

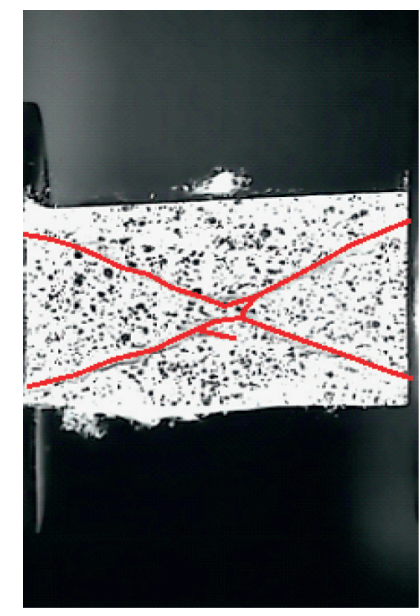

(e)

Figure 7: Impact damage image of fine sandstone. (a) $18^{\circ} \mathrm{C}$. (b) $40^{\circ} \mathrm{C}$. (c) $60^{\circ} \mathrm{C}$. (d) $80^{\circ} \mathrm{C}$. (e) $100^{\circ} \mathrm{C}$.

TABLE 2: Digital image correlation analysis parameters for the fine sandstone surface displacement.

\begin{tabular}{lcccccc}
\hline Sample & $\begin{array}{c}\text { Temperature } \\
\left({ }^{\circ} \mathrm{C}\right)\end{array}$ & $\begin{array}{c}\text { Bullet incident velocity } \\
(\mathrm{m} / \mathrm{s})\end{array}$ & $\begin{array}{c}\text { Dynamic load action } \\
\text { time }(\mathrm{ms})\end{array}$ & $\begin{array}{c}\text { Impact test parameters DIC processing parameters } \\
\text { CCD acquisition } \\
\text { frequency }(\mathrm{Hz})\end{array}$ & $\begin{array}{c}\text { Resolution } \\
\text { (pixel) }\end{array}$ & $\begin{array}{c}\text { Subset } \\
\text { Step }\end{array}$ \\
\hline S1 & 18 & 1.31 & 0.788 & 14000 & $640 \times 480$ & 21 \\
\hline
\end{tabular}

sample are shown in Figures 11(a) and 11(b). The strains at $12 \#$ and $13 \#$ are compressive, while the strain at $1 \#$ changes between compressive and tensile. A strain concentration area appears in the lower part of the sample. The compressive strain gradually decreases from the center line to the edge of the sample. As the dynamic load stress increases, the horizontal strain shows a trend of first increasing, then decreasing, and then increasing again. In the postpeak stress stage, the compressive strain decreases, and the tensile strain increases, similar to the "W" shape change law. The vertical strain is similar to the horizontal strain, also presenting a "W" shape. An abnormal area appears at the lower left end of the sample (at 11\#, 12\#, and 13\#), and the strain varies between compression and tension.

\section{Discussion}

The coal-measure fine sandstone was a heterogeneous material composed of pores, microcracks, joints, and other microstructures. During the impact experiments, there were several differences in the experimental results due to sample differences, human operations, and temperature effects on the incident and transmission rods. However, to a certain extent, these errors do not affect the macro-response 


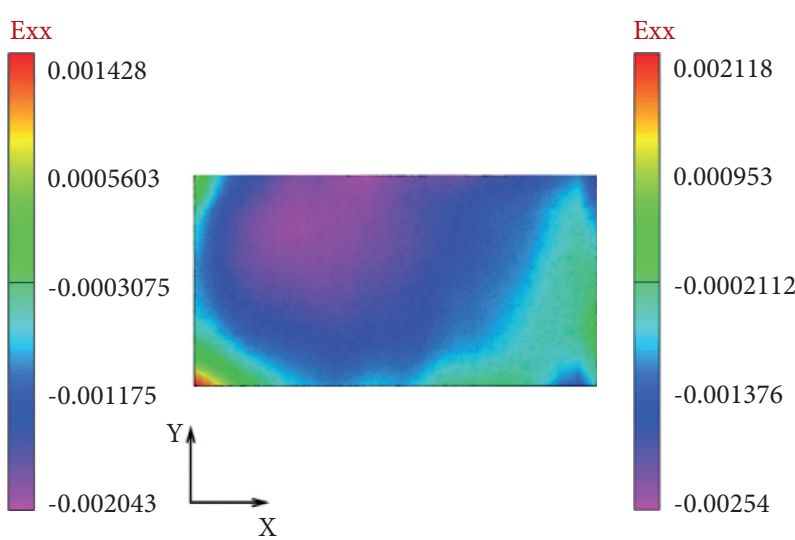

(a)
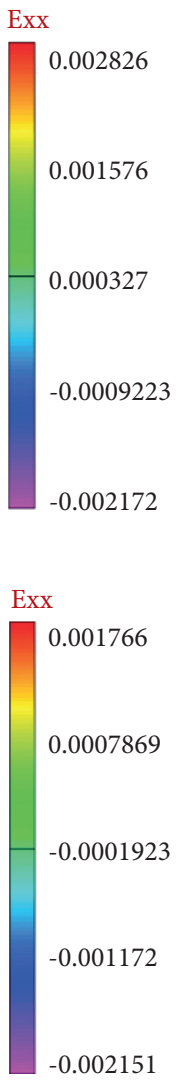

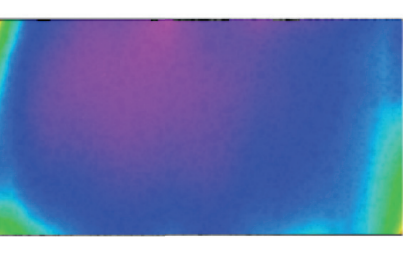

(c)

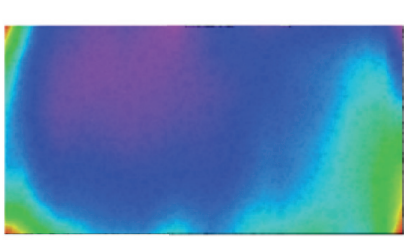

(e)

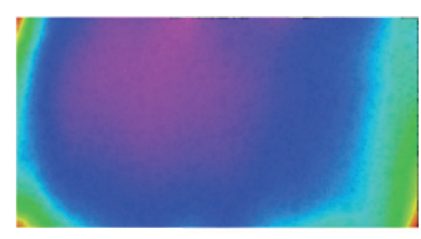

(b)
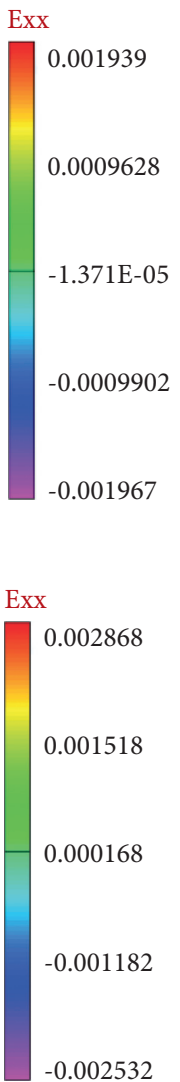

(d)
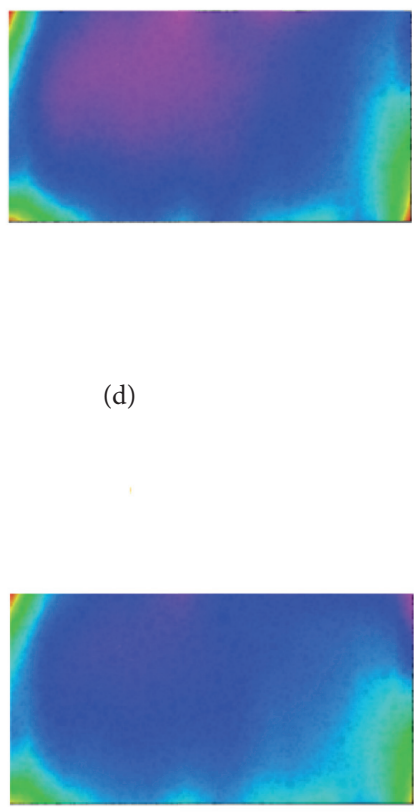

(f)

FIGURE 8: Surface strain cloud diagrams of the fine sandstone impact tests (horizontal direction). (a) $15 \% \sigma$ p. (b) $20 \% \sigma$ p. (c) $55 \% \sigma$ p. (d) $95 \%$ $\sigma$ p. (e) $100 \% \sigma$ p. (f) $90 \%$ post $\sigma_{\mathrm{p}}$.

between the physical impact and mechanical parameters of the fine sandstone and the temperature. As shown in Figure 5 , as the temperature increases, the dynamic load peak strength of the fine sandstone shows an increasing trend; however, the relative increase in its peak strength increases or decreases. The relative increase in the strength was $1.14 \mathrm{MPa}\left({ }^{\circ} \mathrm{C}\right)$ when the temperature increased from $40^{\circ} \mathrm{C}$ to $60^{\circ} \mathrm{C}, 0.15 \mathrm{MPa}\left({ }^{\circ} \mathrm{C}\right)$ when the temperature increased from $60^{\circ} \mathrm{C}$ to $80^{\circ} \mathrm{C}$, and $0.62 \mathrm{MPa}\left({ }^{\circ} \mathrm{C}\right)$ when the temperature increased from $80^{\circ} \mathrm{C}$ to $100^{\circ} \mathrm{C}$. This is primarily due to the close interactions between the impact load, axial static load, temperature, and constant temperature time during the impact tests. Under the condition in which the temperature is not more than $100^{\circ} \mathrm{C}$, the water in the fine sandstone sample evaporates rapidly, the density decreases, the temperature accelerates the crack propagation, and, at the same time, the bearing capacity of the sample improves after dynamic loading (the postpeak strength of the fine sandstone is shown in Figure 4). The stress "rebound" phenomenon in the fine sandstone dynamic stress-strain curve shown in Figure 4 is universal and is consistent with previous research results [46]. 

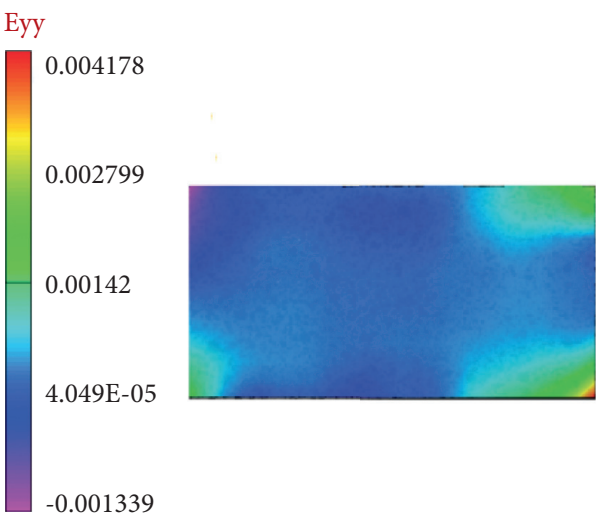

(a)
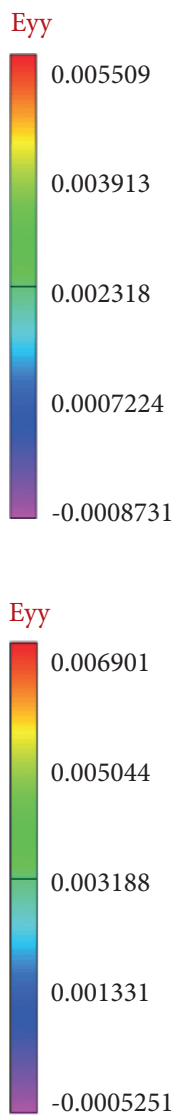

(c)

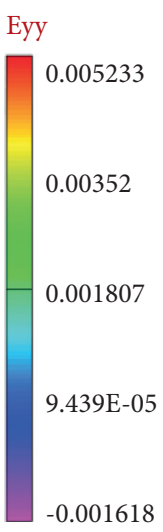

$-0.001618$
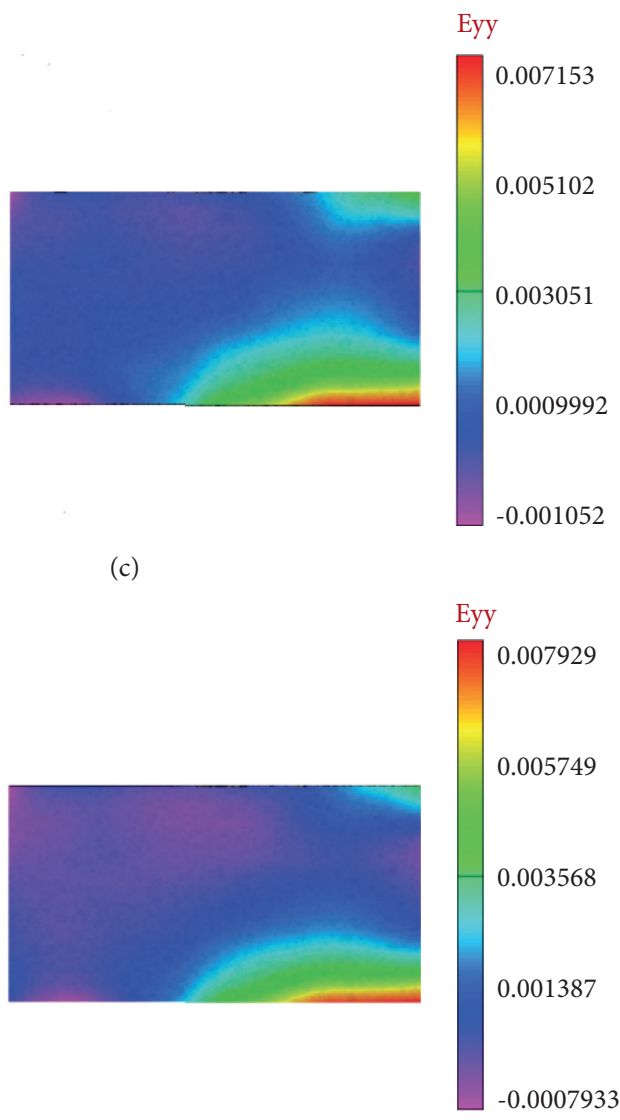

(e)

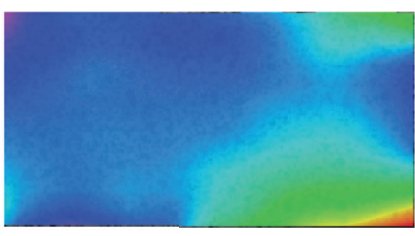

(b)

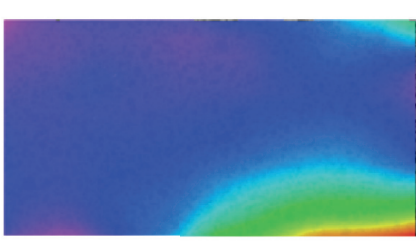

(d)

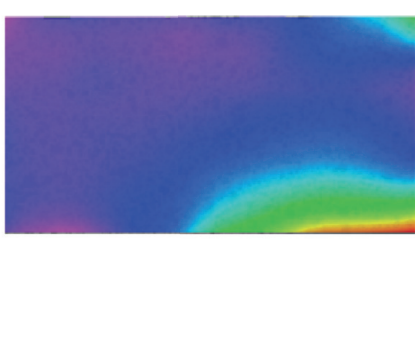

(f)

FiguRE 9: Surface strain cloud diagrams of the fine sandstone impact test (vertical direction). (a) $15 \% \sigma_{\mathrm{p}}$. (b) $20 \% \sigma_{\mathrm{p}}$. (c) $55 \% \sigma_{\mathrm{p}}$. (d) $95 \% \sigma_{\mathrm{p}}$. (e) $100 \% \sigma_{\mathrm{p}}$. (f) $90 \%$ post $\sigma_{\mathrm{p}}$.

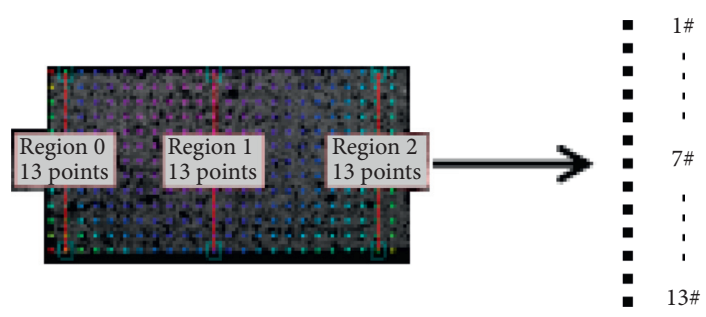

FiguRE 10: Schematic diagram of point strain component extraction on fine sandstone surface. 


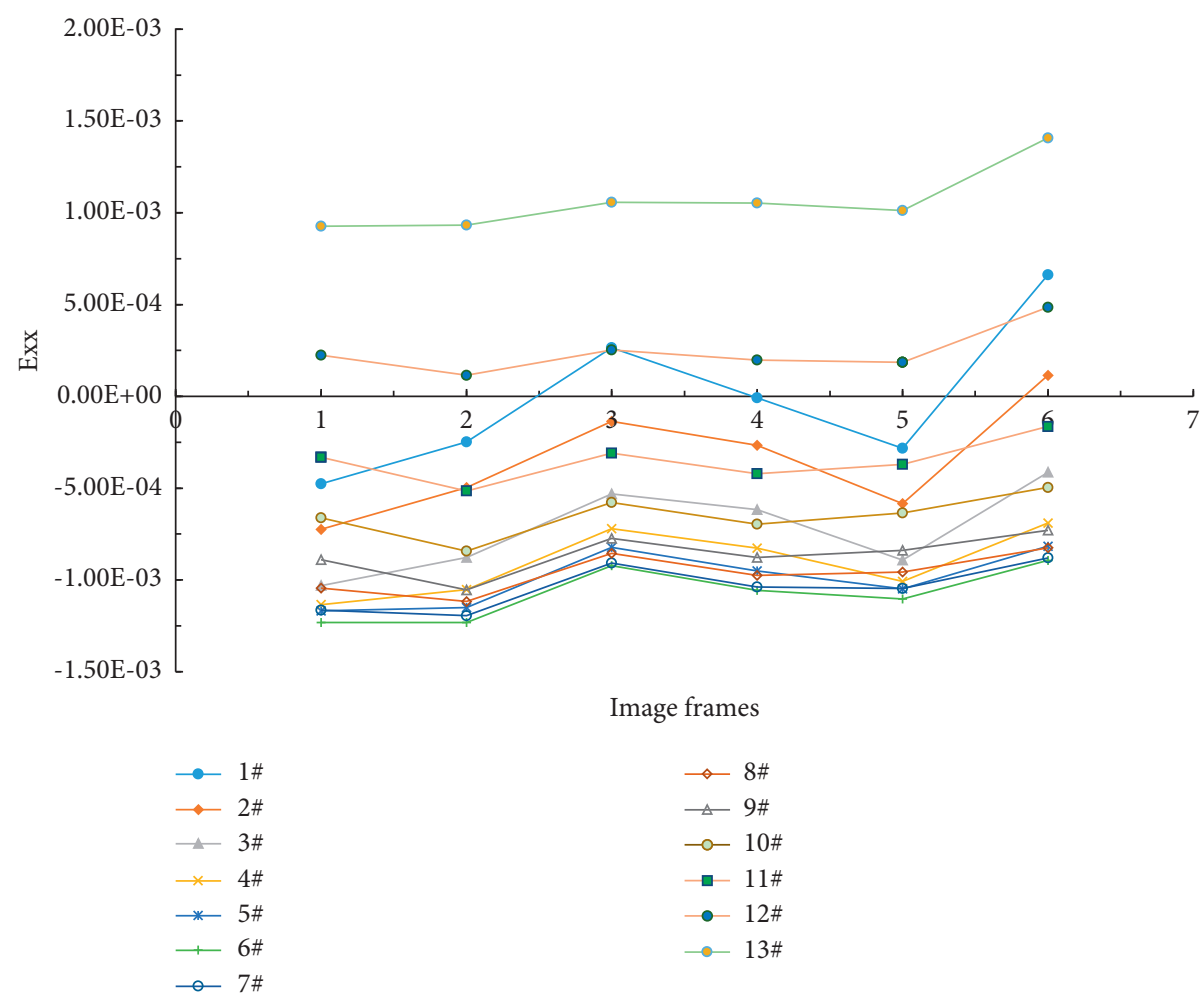

(a)

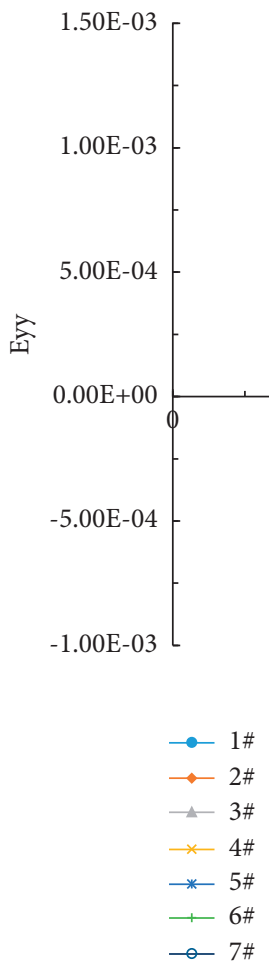

Image frames

$$
\begin{aligned}
& -8 \# \\
& -9 \# \\
& \triangle 10 \# \\
& -11 \# \\
& \rightarrow-12 \# \\
& -13 \#
\end{aligned}
$$

(b)

Figure 11: Continued. 

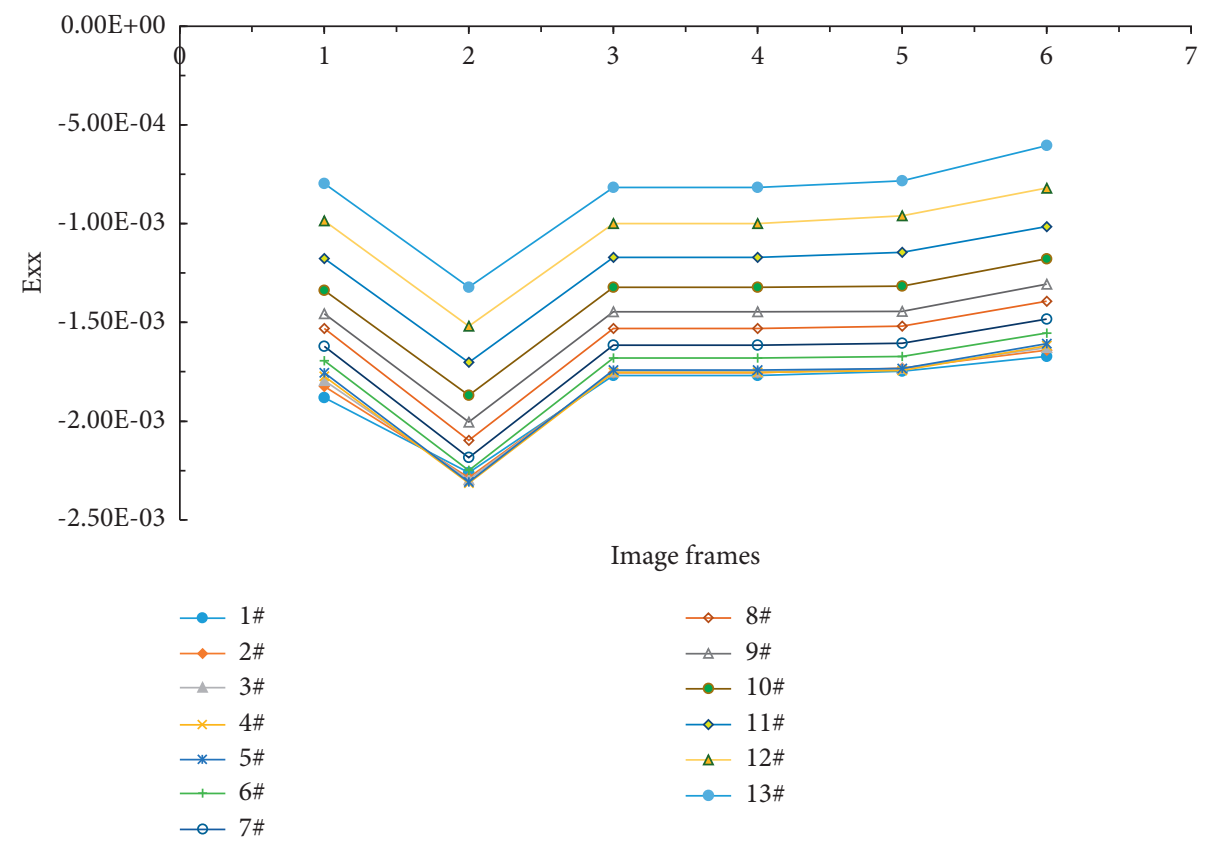

(c)

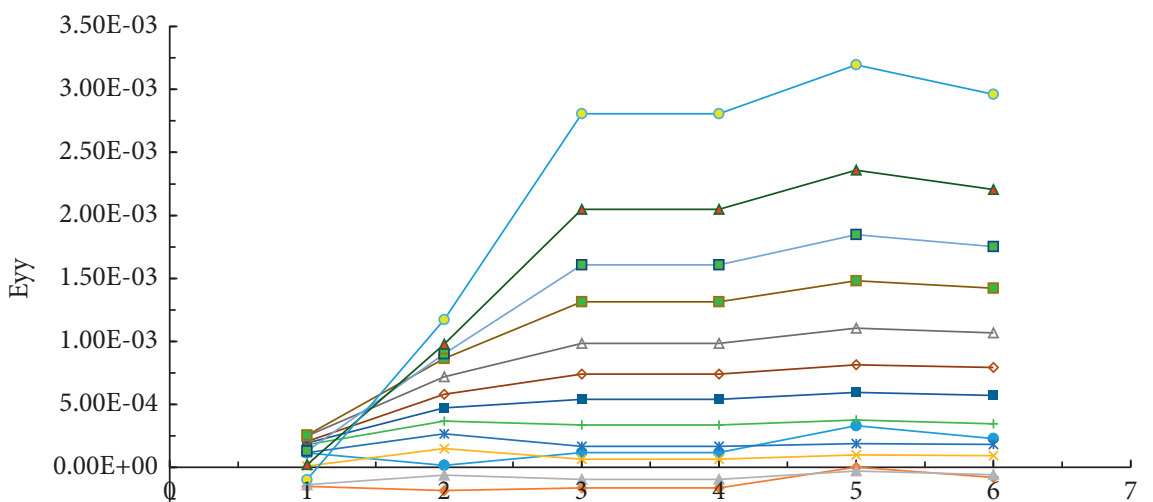

$-5.00 \mathrm{E}-04$

$$
\begin{aligned}
& \rightarrow \text { 1\# } \\
& \rightarrow-2 \# \\
& -6 \text { 3\# } \\
& -* \text { 4\# } \\
& \rightarrow 5 \# \\
& -6 \# \\
& -7 \text { 7\# }
\end{aligned}
$$

Image frames

$$
\begin{aligned}
& -8 \# \\
& -9 \# \\
& --10 \# \\
& -11 \# \\
& -12 \# \\
& --13 \#
\end{aligned}
$$

(d)

FIgure 11: Continued. 


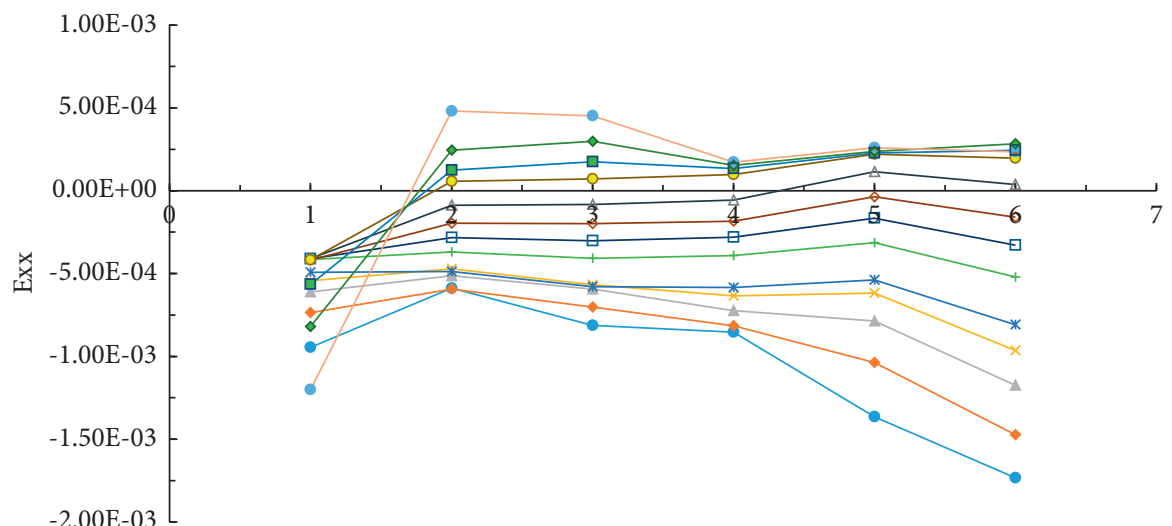

Image frames

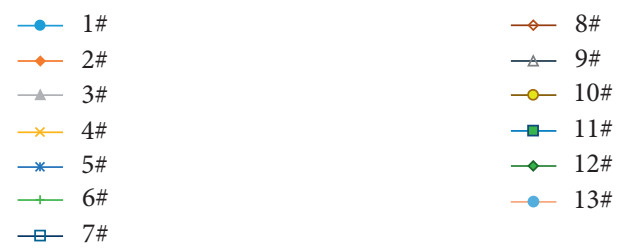

(e)
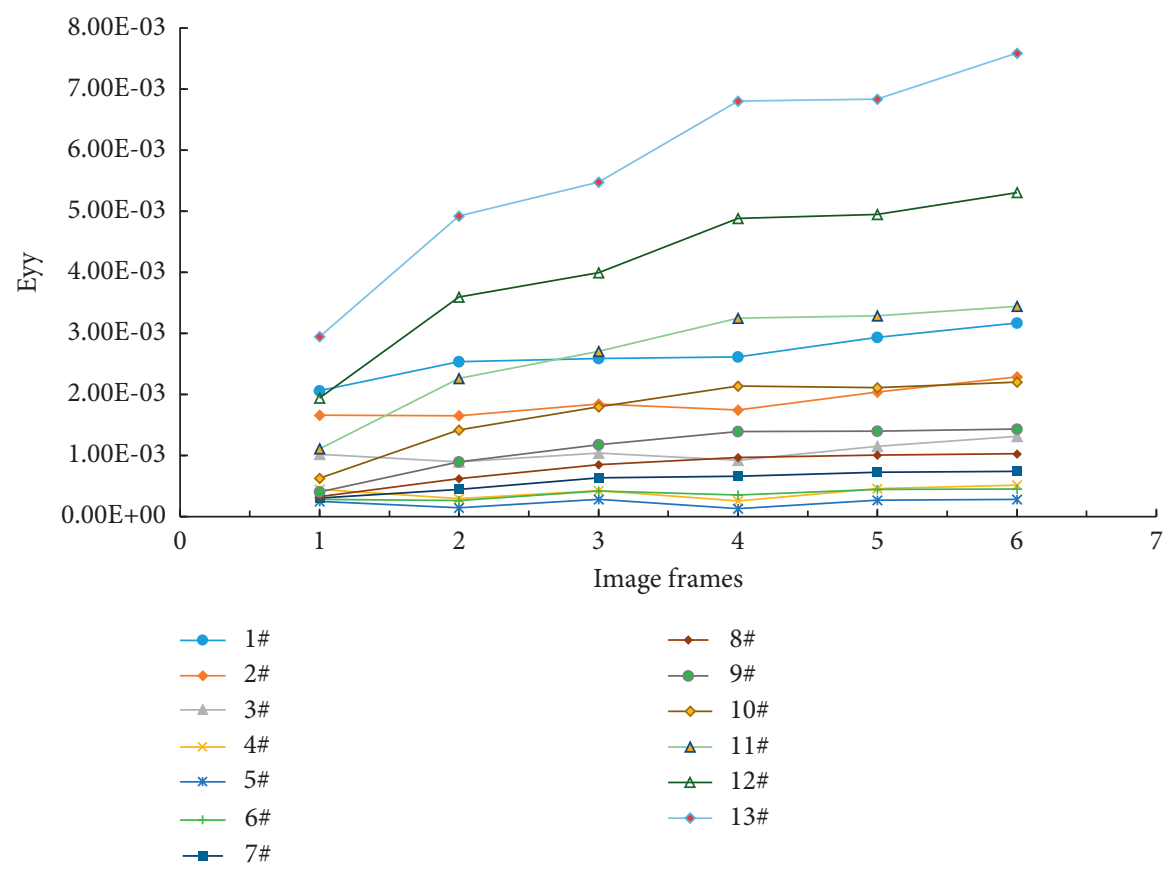

(f)

FIgURE 11: Surface strain curves of the fine sandstone in the three regions defined in Figure 10. (a) Region 0. (b) Region 0. (c) Region 1. (d) Region 1. (e) Region 2. (f) Region 2.

The DIC analysis indicates that the crack propagation of the fine sandstone under the impact load is basically in a "shear" mode (Figure 7). Under the condition of no lateral restraint and under the action of a dynamic load stress wave in the fine sandstone, a displacement vector change phenomenon is observed near the two end faces of the sample (Figure 11). In the middle of the sample, the $X$-direction shows complete compressive strain, and the $Y$-direction shows the displacement vector change phenomenon. Under the theoretical conditions of displacement continuity, the fine sandstone very easily forms a shear failure.

In the process of deep mining, the instability and destruction of the surrounding rock structure or the occurrence of rock burst disasters primarily originate from the fracture behavior of the roof and floor rocks, which provide the main source of energy. An analysis of the dissipation characteristics of the fine sandstone during the dynamic loading process from an energy point of view is shown in Figure 6. When the stress wave 
penetrates the sample, the incident energy, reflected energy, and dissipation energy rapidly increase to a certain value and then remain relatively stable. The transmitted energy is relatively small and can be approximated as a straight line, which is in agreement with the energy dissipation characteristics of rock impulse mechanics. As the temperature increases, most of the incident energy in the fine sandstone is dissipated in the form of reflected waves; however, at $100^{\circ} \mathrm{C}$, the sample experiences a phenomenon in which the dissipation energy is higher than the reflected energy [47]. The excessively high proportion of reflected energy originates from the combination of the incident rod, sample, and transmission rod. In actual engineering situations, rock formations, coal seams, and mudstone formations may alternate, and high-energy consumption may occur as the temperature increases. Intensifying the damage of the rock formation, the existence of high ground stress may also affect the damage degree of the rock formation and the development of cracks. Therefore, deep coal and rock masses are in a complex mechanical environment of "three highs and one disturbance." These issues need to be considered in depth when implementing surrounding rock support engineering practices and in the monitoring and early warning of rock bursts.

\section{Conclusions}

(1) With increasing temperature $\left(18-100^{\circ} \mathrm{C}\right)$, the dynamic load peak strength of the impact-type fine sandstone shows an increasing trend and the peak strain shows a trend of first decreasing and then increasing, with both trends conforming to a cubic polynomial relationship. The dynamic stress-strain curve of the fine sandstone presents a bimodal shape with an obvious "rebound" phenomenon. The increase in the temperature causes the compaction stage of the rock to disappear.

(2) Using a DIC analysis, it was found that the fine sandstone experiences displacement vector changes at both ends and in the middle of the sample under the action of dynamic stress waves. In addition, the strain along the propagation direction of the stress wave is higher than that in other directions. The failure form of the fine sandstone is shear failure.

(3) From the perspective of the energy analysis, the incident energy, reflected energy, and dissipated energy of the fine sandstone rapidly increase to a certain value under the impact load and then remain relatively stable. As the temperature increases, most of the incident energy in the fine sandstone is dissipated in the form of reflected waves.

\section{Data Availability}

The numerical simulation data used to support the findings of this study are included within the article.

\section{Conflicts of Interest}

The authors declare that they have no conflicts of interest.

\section{Acknowledgments}

This work was financially supported by the National Natural Science Foundation of China (52004267, 52074276 and 51504244).

\section{References}

[1] B. Huang, N. Zhang, H. Jing et al., "Large deformation theory of rheology and structural instability of the surrounding rock in deep mining roadway," Journal of China Coal Society, vol. 45, no. 3, pp. 911-926, 2020.

[2] M. He, H. Xie, S. Peng, and Y. Jiang, "Study on rock mechanics in deep mining engineering," Chinese Journal of Rock Mechanics and Engineering, vol. 24, no. 16, pp. 2803-2813, 2005.

[3] Q. Qian, "The characteristic scientific phenomena of engineering response to deep rock mass and the implication of deepness," Journal of East China Institute of Technology, vol. 27, no. 1, pp. 1-5, 2004.

[4] M. He, X. Lu, and H. Jing, "Characters OF surrounding rockmass IN deep engineering and its NON-linear dynamicmechanical design concept," Chinese Journal of Rock Mechanics and Engineering, vol. 21, no. 8, pp. 1215-1224, 2002.

[5] S. Ellwood, L. J. Griffiths, and D. J. Parry, "Materials testing at high constant strain rates," Journal of Physics E: Scientific Instruments, vol. 15, no. 3, pp. 280-282, 1982.

[6] Y. Cui, F. Lu, Y. lin, D. Tan, J. Chen, and Y. Wang, "Review on dynamic shear techniques by HoPkinson bars," in Proceedings of the 4th National Conference on experimental technology of explosive mechanics, pp. 1-10, 2006.

[7] Y. Li, T. Suo, J. Shi, and W. Guo, Experimental Device of Material Dynamic Double Compression Shear Based on Hopkinson Bar, China, 2010.

[8] R. Xie, F. Zhang, Y. Yan et al., "High-temperature SHPB experimental technique and its application," Explosion and Shock Waves, vol. 25, no. 4, pp. 330-334, 2005.

[9] M. A. Dan, H. Duan, J. Zhang, X. Feng, and Y. Huang, "Experimental investigation of creep-erosion coupling mechanical properties of water inrush hazards in fault," Fracture Rock Masses, vol. 40, no. 9, pp. 1751-1763, 2021.

[10] K. Xia, J. Cheng, and S. Hu, "Application of SHPB apparatus to the measurement of high temperature dynamical mechanical behavior of materials," Journal of Experimental Mechanics, vol. 13, no. 3, pp. 307-313, 1998.

[11] R. J. Christensen, S. R. Swanson, and W. S. Brown, "Split Hopkinson Bar tests on rocks under confining pressure," Experimental Mechnics, vol. 12, no. 12, pp. 508-513, 1973.

[12] U. S. Lindholm, L. M. Yeakley, and A. Nagy, "The dynamic strength and fracture properties of dresser basalt," International Journal of Rock Mechanics and Mining Science \& Geomechanics Abstracts, vol. 11, no. 5, pp. 181-191, 1974.

[13] Y. Yu, "Study on dynamic load characteristics of rock by triaxial SHPB device," Journal of geotechnical engineering, vol. 14, no. 3, pp. 76-79, 1992.

[14] L. Dou, H. Jiang, and A. Cao, "Rock burst prevention methods based on theory of dynamic and static combined load induced in coal mine," Journal of China Coal Society, vol. 40, no. 7, pp. 1469-1476, 2015.

[15] X. Kong, Study on Dynamics Behaviors and Gas Releasing Characteristics of Gas-Bearing Coal under Dynamic Load, China University of Mining \& Technology, Xuzhou, 2018. 
[16] A. Gilat and X. Wu, "Elevated temperature testing with the torsional split Hopkinson bar," Experimental Mechanics, vol. 34, no. 2, pp. 166-170, 1994.

[17] D. Ma, J. Wang, X. Cai et al., "Effects of height/diameter ratio on failure and damage properties of granite under coupled bending and splitting deformation," Engineering Fracture Mechanics, vol. 220, p. 106640, 2019.

[18] K. P. Chong, P. M. Hoyt, J. W. Smith, and B. Y. Paulsen, "Effect of strain rate on oil shale fracturing," Int J Rock Mech Min, vol. 17, pp. 35-43, 1980.

[19] D. E. Grady, "The mechanics of fracture under high-rate stress loading," in Proceedings of the International union of theoretical and applied mechanics conference on geomaterials: rocks, concretes, soils, Evanston, pp. 129-155, Mechanics of Geomaterials, United States: N. p., September 1983.

[20] R. Zhu and M. Wu, "Failure criterion of granite at different loading rates," Explosion and Shock Waves, vol. 5, no. 1, pp. 1-8, 1984.

[21] W. Wang, Y. Liu, Y. Lu, and J. Zhang, "Development of RDT10000 type rock high pressure dynamic triaxial machine," Rock and Soil Mechanics, vol. 10, no. 2, pp. 69-82, 1989.

[22] M. Friedman, R. D. Perkins, and S. J. Green, "Observation of brittle-deformation features at maximum stress of westly granite and solenhofen limestone," International Journal of Rock Mechanics and Mining Sciences, vol. 7, pp. 297-306, 1970.

[23] W. Janach, "The role of bulking in brittle failure of rock under rapid compression," International Journal of Rock Mechanics and Mining Sciences, vol. 13, pp. 177-186, 1976.

[24] X. Li, S. Chen, and D. Gu, "Dynamic strength of rock under impulse loads with diferent stress wave forms and durations," Journal of Central-South Institute of Mining and Metallurgy, vol. 25, no. 3, pp. 301-304, 1994.

[25] X. Li, Rock Dynamics Fundamentals and Application[M], Science Press, Beijing, 2014.

[26] W. Lou, "Dynamic fracture behaviour of dry and waterlogged granites," Explosion and Shock Waves, vol. 14, no. 3, pp. 249-254, 1994.

[27] R. Shan, S. Chen, and B. Li, "Experimental study of granite constitutive properties under uniaxial impact," Explosion and Shock Waves, vol. 20, no. 1, pp. 32-38, 2000.

[28] D. Ma, S. B. Kong, Z. H. Li, Q. Zhang, Z. H. Wang, and Z. L. Zhou, "Effect of wetting-drying cycle on hydraulic and mechanical properties of cemented paste backfill of the recycled solid wastes," Chemosphere, vol. 282, p. 131163, 2021.

[29] Q. Z. Wang, W. Li, and X. L. Song, "A method for testing dynamic tensile strength and elastic modulus of rock materials using SHPB," Pure And Applied Geophysics, vol. 163, no. 13, pp. 1091-1100, 2006.

[30] L. Ting, D. Xi, and S. Xu, "Investigation of the non-linear elastic responses of rock under impact loading," Earth Science Frontiers, vol. 13, no. 3, pp. 206-212, 2006.

[31] X. Liu, S. Song, Y. Tan et al., "Similar simulation study on the deformation and failure of surrounding rock of a large section chamber group under dynamic loading," International Journal of Mining Science and Technology, vol. 31, pp. 495-505, 2021.

[32] X. Liu, D. Fan, Y. Tan et al., "New detecting method on the connecting fractured zone above the coal face and a case study," Rock Mechanics and Rock Engineering, vol. 54, no. 1-2, pp. 1-13, 2021.

[33] X. Liu, D. Fan, Y. Tan et al., "Failure evolution and instability mechanism of surrounding rock for close-distance chambers with super-large section in deep coal mines," International
Journal of Geomechanics, vol. 21, no. 5, Article ID 04021049, 2021.

[34] C. Xia, H. Xie, Y. Ju, and H. Zhou, "Experimental study of energy dissipation of porous rock under impact loading," Engineering Mechanics, vol. 23, no. 9, pp. 1-5, 2006.

[35] Y. Zhai, G. Ma, J. Zhao, and H. Changming, "Dynamic failure analysis on granite under uniaxial impact compressive load," Chinese Journal of Geotechnical Engineering, vol. 29, no. 3, pp. 385-390, 2007.

[36] H. Liang, X. Li, C. Ma, T. Yin, Z. Ye, and G. Liao, "Study on size effect of rock dynamic strength and strain rate sensitivity," Chinese Journal of Rock Mechanics and Engineering, vol. 27, no. 3, pp. 526-533, 2008.

[37] X. Song, Q. Wang, and H. Xie, "Failure strain of Brazilian disc samples of marble after high temperature under dynamic split tests," Journal of Sichuan University (Engineering Science Edition), vol. 40, no. 1, pp. 38-43, 2008.

[38] G. Wan, X. Li, and T. Yin, "Experimental research on destruction portent of post-high temperature sandstone," Metal Mine, vol. 7, pp. 129-131, 2008.

[39] M. Li, Research on Rupture Mechanisms of Coal Measures Sand-Stone under High Temperature and Impact load[D], China University of Mining and Technology, Xuzhou, 2014.

[40] T. Yin, R. Shu, X. Li, P. Wang, and L. Dong, "Combined effects of temperature and axial pressure on dynamic mechanical properties of granite," Transactions of Nonferrous Metals Society of China, vol. 26, pp. 2209-2219, 2016.

[41] R. Shu, T. Yin, and X. Li, "Effect of thermal treatment on energy dissipation of granite under cyclic impact loading," Transactions of Nonferrous Metals Society of China, vol. 29, no. 2, pp. 385-396, 2019.

[42] R. Zhang and L. Jing, "Analysis on the fragment and energy dissipation of deep sandstone after high/low temperature treatment in SHPB tests," Journal of China Coal Society, vol. 43, no. 7, pp. 1884-1892, 2018.

[43] L. Yu, T. Zhang, Z. Zhu, H. Su, P. Fan, and Y. Wang, "An experimental investigation of physical and dynamic mechanical behaviors of marble after heat treatment in quasivacuum and air-filled Environments," J. Cent. South Univ.vol. 28, no. 9, pp. 2770-2785, 2021.

[44] D. Ma, J. Zhang, H. Duan et al., "Reutilization of gangue wastes in underground backfilling mining: overburden aquifer protection," Chemosphere, vol. 264, p. 128400, 2021.

[45] B. Lunberg, "A split Hopkinson bar study of energy absorption in dynamic rock fragmentation," International Journal of Rock Mechanics and Mining Science \& Geomechanics Abstracts, vol. 13, no. 6, pp. 187-197, 1976.

[46] J. Feng, E. Wang, R. Shen, L. Chen, X. Li, and Z. Xu, "Investigation on energy dissipation and its mechanism of coal under dynamic loads," Geomechanics and Engineering, vol. 11, no. 5, pp. 657-670, 2016.

[47] X. Liu, L. Yu, F. Zhao, Y. Zhou, W. Wang, and S. Li, "Experimental research on mechanical and energy characteristics of reinforced rock under dynamic loading," Shock and Vibration, vol. 2019, pp. 1-11, Article ID 4356729, 2019. 